\title{
Optimal use of topical minoxidil in management of female pattern hair loss in India: an expert opinion
}

\author{
Venkatram Mysore', Rachita Dhurat ${ }^{2}$, Anil Abraham ${ }^{3}$, D. M. Thappa ${ }^{4}$, Pradeep Kumari', \\ Rashmi Sarkar ${ }^{5}$, Rajetha Damisetty ${ }^{6}$, Uday Khopkar ${ }^{7}$, Snehal Mucchala ${ }^{8}$, Rahul Rathod ${ }^{8}$, \\ Monil Yogesh Neena Gala ${ }^{8 *}$
}

\begin{abstract}
${ }^{1}$ Department of Dermatology, Venkat Centre for Skin and Plastic Surgery, Karnataka, India
${ }^{2}$ Department of Dermatology, LTM Medical College and LTMG Hospital, Sion, Mumbai, Maharashtra, India

${ }^{3}$ Department of Dermatology, Abrahams Skin and Hair Clinic, Karnataka, India

${ }^{4}$ Department of Dermatology and STD Department, JIPMER, Puducherry, India

${ }^{5}$ Department of Dermatology, Lady Hardinge Medical College, New Delhi, India

${ }^{6}$ Department of Dermatology, Dr. Rajetha's Mohana Skin and Hair Clinic, Hyderabad, India

${ }^{7}$ Department of Dermatology, KEM Hospital and GS Medical College, Mumbai, Maharashtra, India

${ }^{8}$ Department of Medical Affairs, Dr. Reddy’s Laboratories, Hyderabad, Telangana, India
\end{abstract}

Received: 10 November 2021

Accepted: 16 December 2021

\section{*Correspondence:}

Dr. Monil Yogesh Neena Gala,

E-mail: monil.yogesh@drreddys.com

Copyright: () the author(s), publisher and licensee Medip Academy. This is an open-access article distributed under the terms of the Creative Commons Attribution Non-Commercial License, which permits unrestricted non-commercial use, distribution, and reproduction in any medium, provided the original work is properly cited.

\begin{abstract}
Female pattern hair loss (FPHL) is a common cause of hair loss and is associated with a reduction in quality of life and psychological morbidity. It is characterised by nonscarring progressive thinning of hair with gradual reduction in the number of hairs, with prevalence increasing with advancing age. A differential diagnosis of FPHL includes conditions like chronic telogen effluvium, diffuse alopecia areata, and some cases of scarring alopecia such as frontal fibrosing alopecia. A comprehensive history and thorough clinical examination are essential in establishing the diagnosis of FPHL. Additionally, dermoscopy is a valuable tool for appropriate diagnosis, specifically in early stages of the disease. Due to the chronic course and progressive nature of FPHL, long-term management is essential for sustained effects. Medical treatment with minoxidil remains the mainstay treatment for FPHL. Other therapeutic modalities include topical therapies like biomimetic peptides, systemic therapies like oral anti-androgen drugs such as finasteride and spironolactone as well as oral minoxidil in selected cases. Dermatosurgical procedures like platelet rich plasma, microneedling, low level laser and hair transplantation have been used. The role of diet has also been debated. The current article provides an overview on the optimal use of topical minoxidil for management of FPHL in Indian clinical practice.
\end{abstract}

Keywords: Minoxidil, FPHL, Androgenetic alopecia, Treatment

\section{INTRODUCTION}

Female pattern hair loss (FPHL) is a commonly occurring hair loss disorder in women. Onset is usually in adults, though initial symptoms may develop during adolescence. It is characterised as a nonscarring diffuse alopecia that develops from progressive miniaturization of hair follicles and consequent decrease in hair, particularly in the central, frontal, and parietal scalp regions in a characteristic pattern. ${ }^{1}$ FPHL has a major impact on the quality of life of an individual. In spite of its high frequency and relevance of its psychological impact, the pathogenesis is not completely understood till date. It is influenced by genetic, hormonal and environmental factors and shows variable response to treatment. ${ }^{2}$ A detailed history, clinical examination, hair 
loss evaluation tests and dermoscopy aid in establishing the diagnosis of FPHL. Currently, several medical and surgical modalities are available for treatment of this entity. Of all therapies, topical minoxidil continues to be the first-line of treatment. ${ }^{3}$

Minoxidil 2\% twice daily solution and 5\% foam once daily have been approved by the food and drug administration (FDA). ${ }^{1,3}$ The current article provides a comprehensive overview of evidence-based literature and clinical insights of expert dermatologists on FPHL and its management with a focus on topical minoxidil-based treatment.

\section{EPIDEMIOLOGY OF FPHL}

The frequency of FPHL differs among population groups and increases with age. ${ }^{2}$ The age of onset for FPHL is during the reproductive years, which is later than in men. A study found that $12 \%$ of women first develop clinically detectable FPHL by age 29 years. Furthermore, 25\% develop it by 49 years, $41 \%$ by 69 years and more than $50 \%$ of women have some element of FPHL by 79 years. ${ }^{1}$ There is a second peak incidence at menopause, between 50 and 60 years of age. ${ }^{2}$

The occurrence of prepubertal androgenetic alopecia (AGA) has rarely been reported. Polycystic ovarian syndrome (PCOS) and other causes of hyperandrogenism may present with hair loss in an androgenetic pattern. ${ }^{4}$

\section{Consensus key-point 1}

According to experts, the prevalence of FPHL is increasing and age of onset is decreasing. With increasing age, the incidence of FPHL tends to increase. There has been a recent increase in the number of cases of AGA in adolescents and pre-adolescent females. The occurrence of early-onset PCOS is increasing and this could be a cause of the increasing incidence of FPHL.

\section{AETIOPATHOGENESIS AND CAUSES OF FPHL}

FPHL is polygenic and multifactorial with a complex aetiopathogenesis which involves an interplay of genetic, hormonal, and environmental factors. In FPHL, a decrease in duration of anagen phase occurs along with miniaturization of dermal papilla. Miniaturization is the hallmark feature in FPHL which involves progressive transformation of terminal hair follicles to vellus-like hair follicles. These vellus-like hair follicles have a shortened hair cycle due to decrease in the anagen phase, which subsequently results in production of fine and short hair shafts. Hence, premature termination of the anagen phase is a vital event in development of FPHL. ${ }^{3}$

FPHL is often precipitated by factors like medications, weight loss, and hormonal therapies. It is also associated with other signs of hyperandrogenism like acne or hirsutism. ${ }^{5}$ Additional factors like psychological stress, hypertension, diabetes mellitus, smoking, etc. could be related to FPHL (Figure 1). ${ }^{3}$

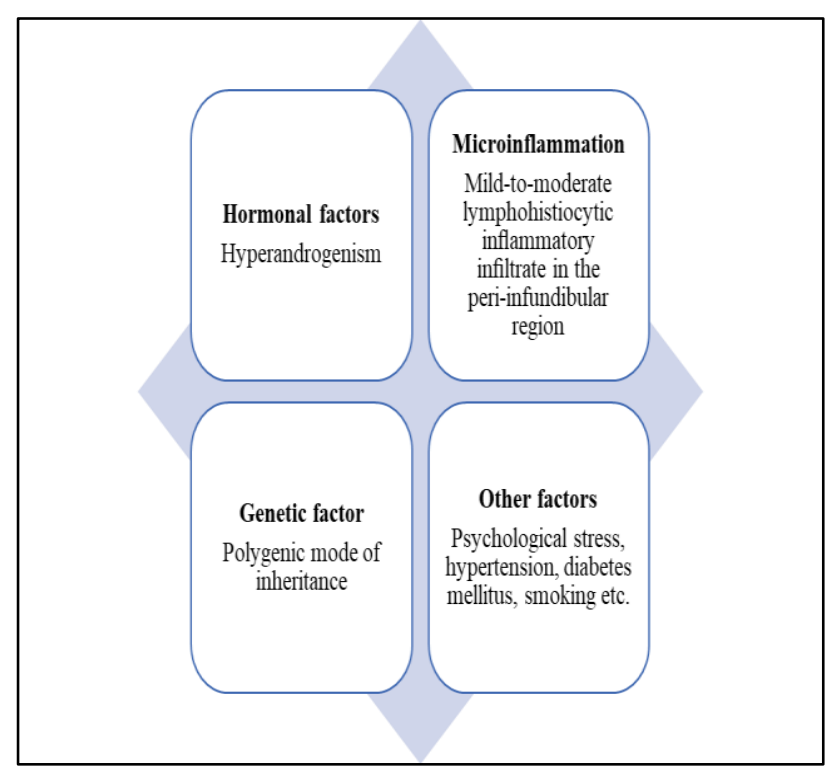

Figure 1: Factors involved in FPHL.

\section{Consensus key-point 2}

The experts agreed to the above stated evidence of FPHL being a multifactorial entity.

\section{CLASSIFICATION OF FPHL}

Various classification systems have been proposed for FPHL based on the evolutionary stage of hair loss. ${ }^{6}$ The pattern of diffuse thinning of the upper biparietal and vertex region, preserving the anterior hair implantation can be classified using Ludwig scale and Sinclair scale (Table 1). ${ }^{2,7,8}$ Even though Ludwig scale is widely used, it does not classify intermediate stages very precisely. ${ }^{2}$ Sinclair's classification subdivides FPHL into five levels of intensity based on the normal scalp, which makes it more relatable to the reality of each patient (Figure 2). ${ }^{2,8,9}$

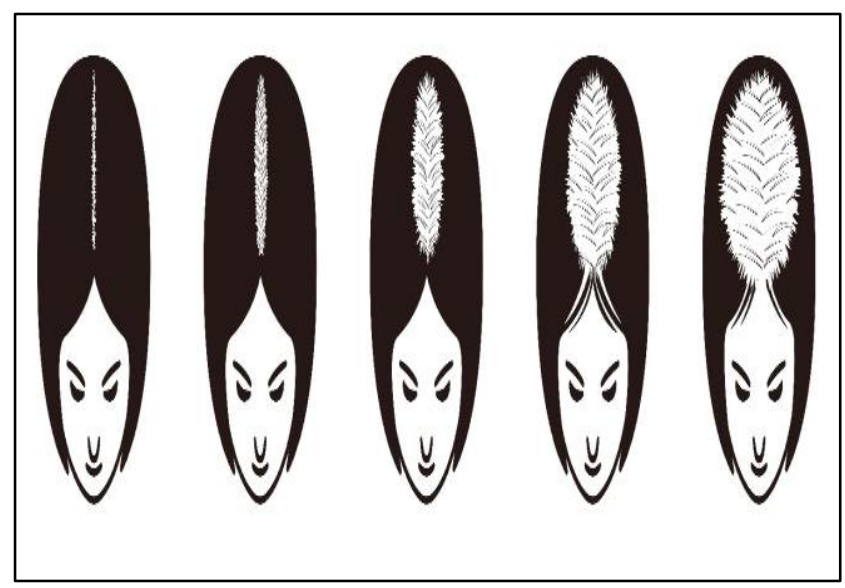

Figure 2: Sinclair's classification (Adapted from Sinclair et al, 2005). ${ }^{5}$ 
Table 1: Classification of FPHL.

\begin{tabular}{|c|c|}
\hline \multicolumn{2}{|c|}{ Classification } \\
\hline Grade I & $\begin{array}{l}\text { Perceptible thinning of the hair on the crown, } \\
\text { limited in the front by a line situated } 1-3 \mathrm{~cm} \\
\text { behind the frontal hairline }\end{array}$ \\
\hline Grade II & $\begin{array}{l}\text { Pronounced rarefaction of the hair on the } \\
\text { crown within the area seen in grade I }\end{array}$ \\
\hline $\begin{array}{l}\text { Grade } \\
\text { III }\end{array}$ & $\begin{array}{l}\text { Full baldness (total denudation) within the } \\
\text { area seen in grades I and II }\end{array}$ \\
\hline \multicolumn{2}{|c|}{ Sinclair scale s,10 $^{8,1}$} \\
\hline Grade 1 & $\begin{array}{l}\text { Normal. This pattern is found in all girls prior } \\
\text { to puberty, but in only } 45 \% \text { of women aged } \\
\text { eighty or above }\end{array}$ \\
\hline Grade 2 & Shows widening of the central part \\
\hline Grade 3 & $\begin{array}{l}\text { Shows widening of the central part and } \\
\text { thinning of hair on either side of the central } \\
\text { part }\end{array}$ \\
\hline Grade 4 & $\begin{array}{l}\text { Shows emergence of a diffuse hair loss over } \\
\text { the top of the scalp }\end{array}$ \\
\hline Grade 5 & Indicates advanced hair loss \\
\hline
\end{tabular}

\section{Consensus key-point 3}

The experts opined that Sinclair scale was more suitable and practical compared to Ludwig scale and should be adopted for routine clinical practice in Indian settings.

\section{DIAGNOSIS OF FPHL}

\section{Patient history and physical examination}

A thorough medical history, detailed drug history and physical examination is essential for every patient of FPHL. ${ }^{3,10}$ A complete gynaecological and obstetrical history must be done for excluding hormonal deregulations. ${ }^{9}$ Impaired fertility, amenorrhoea, irregular menstrual cycle, and signs of hyperandrogenism might indicate underlying PCOS which is the most common endocrinologic comorbidity associated with FPHL., ${ }^{1,9}$ History must include information about chronic illness, nutritional deficiencies, metabolic/endocrine disturbances and recent treatments. ${ }^{11}$

Scalp examination must focus on identifying distribution of hair loss and calibre of hair in commonly involved areas. Detection of terminal hair loss, variation of hair calibre, and miniaturized hairs are indicative of FPHL. Pull test, which identifies increased shedding of telogen hairs is typically negative except in active phases of FPHL. One must also consider scarring alopecia mimicking FPHL like frontal fibrosing alopecia. ${ }^{9}$

\section{Trichoscopy}

Trichoscopy or scalp dermoscopy is a very useful noninvasive diagnostic tool for hair disorders. ${ }^{9}$ It could contribute to the diagnosis of FPHL, especially in early stages. Diversity in thickness of hair with an increased number of miniaturized hairs, especially in the frontoparietal region is considered to be the main dermoscopic finding. A hair diameter density of $>20 \%$ is diagnostic for FPHL. ${ }^{3}$ The handheld dermatoscope allows appreciation of clinical features. Video dermoscopy enables quicker and high-resolution viewing at higher magnifications than the handheld dermatoscope. ${ }^{11}$

\section{Scalp biopsy}

Scalp biopsy is an optimum way to distinguish between chronic telogen effluvium (CTE) and FPHL. A terminal to vellus hair ratio of $<4: 1$ is considered diagnostic of FPHL while a ratio of $>8: 1$ is considered diagnostic of CTE. ${ }^{10}$ A biopsy could also distinguish between FPHL and diffuse alopecia areata. ${ }^{11}$

\section{Laboratory investigations}

Extensive endocrinological investigation is not required for all women with FPHL and is hardly done in those without signs of hyperandrogenism. ${ }^{1,9}$ Appropriate screening investigations in women suspected of hyperandrogenism include serum estimation of androgens, prolactin, follicle-stimulating hormone, luteinizing hormone, 17-hydroxyprogesterone, and oestrogen and screening tests for fasting hyperglycaemia and hyperlipidaemia. One could also evaluate for thyroid disease and iron deficiency anaemia in such women. ${ }^{10}$ Free androgen index (FAI) is also indicated as a screening test. FAI of 5 or greater is indicative of PCOS. ${ }^{3}$

\section{Others}

Other methods to evaluate hair loss include non-invasive methods like questionnaires, standardised and modified wash test, global photographs, phototrichogram, TrichoScan, and surface electron microscopy and semiinvasive methods-trichogram and unit area trichogram. ${ }^{11}$

\section{Consensus key-point 4}

The panel experts opined that the diagnostic methodology would remain same for all grades of Sinclair scale. Trichoscopy is the main diagnostic tool for FPHL in Indian settings. Routine investigations include blood count, serum iron, serum vitamin D and thyroid function tests. Tests for TSH, ferritin and vitamins are done routinely, but FAI and prolactin levels are indicated only in certain patients. It is important to identify whether the condition is normoandrogenic or hyperandrogenic for key therapy decisions. Scalp biopsy is indicated only in specific situations like ruling out diffuse alopecia areata.

\section{Currently available treatment options for FPHL}

Treatment options available for FPHL can be classified as topical and systemic medications out of which only minoxidil $2 \%$ twice daily solution and $5 \%$ foam once 
daily have been approved by the FDA. ${ }^{1}$ Dermatological techniques including surgical techniques are also used. ${ }^{3}$ Currently available treatment options for FPHL are listed in Figure 3 while a simplified diagnostic and treatment algorithm for FPHL is depicted in Figure 4. ${ }^{1,3}$

\begin{tabular}{|c|c|c|}
\hline Topical therapies & Systemic therapies & $\begin{array}{l}\text { Dermatological } \\
\text { procedures }\end{array}$ \\
\hline $\begin{array}{l}\text { - Minoxidil } \\
\text { - Finasteride } \\
\text { - Prostaglandin analogs } \\
\text { (Latanoprost and } \\
\text { bimatoprost) } \\
\text { - Ketoconazole } \\
\text { - Melatonin } \\
\text { - Platelet-rich plasma } \\
\text { - Low-level light therapy }\end{array}$ & $\begin{array}{l}\text { - Finasteride } \\
\text { - Dutasteride } \\
\text { - Cyproterone acetate } \\
\text { - Spironolactone } \\
\text { - Flutamide } \\
\text { - Oral minoxidil } \\
\text { - Nutritional } \\
\text { supplementation }\end{array}$ & $\begin{array}{l}\text { - Hair transplantation } \\
\text { - Microneedling } \\
\text { - Mesotherapy with } \\
\text { growth factors* } \\
\text { - Bioengineered hair } \\
\text { follicle stem cells* } \\
\text { - Dermal sheath cup cells* }\end{array}$ \\
\hline
\end{tabular}

Figure 3: Currently available treatment options for FPHL.

*No definite evidence

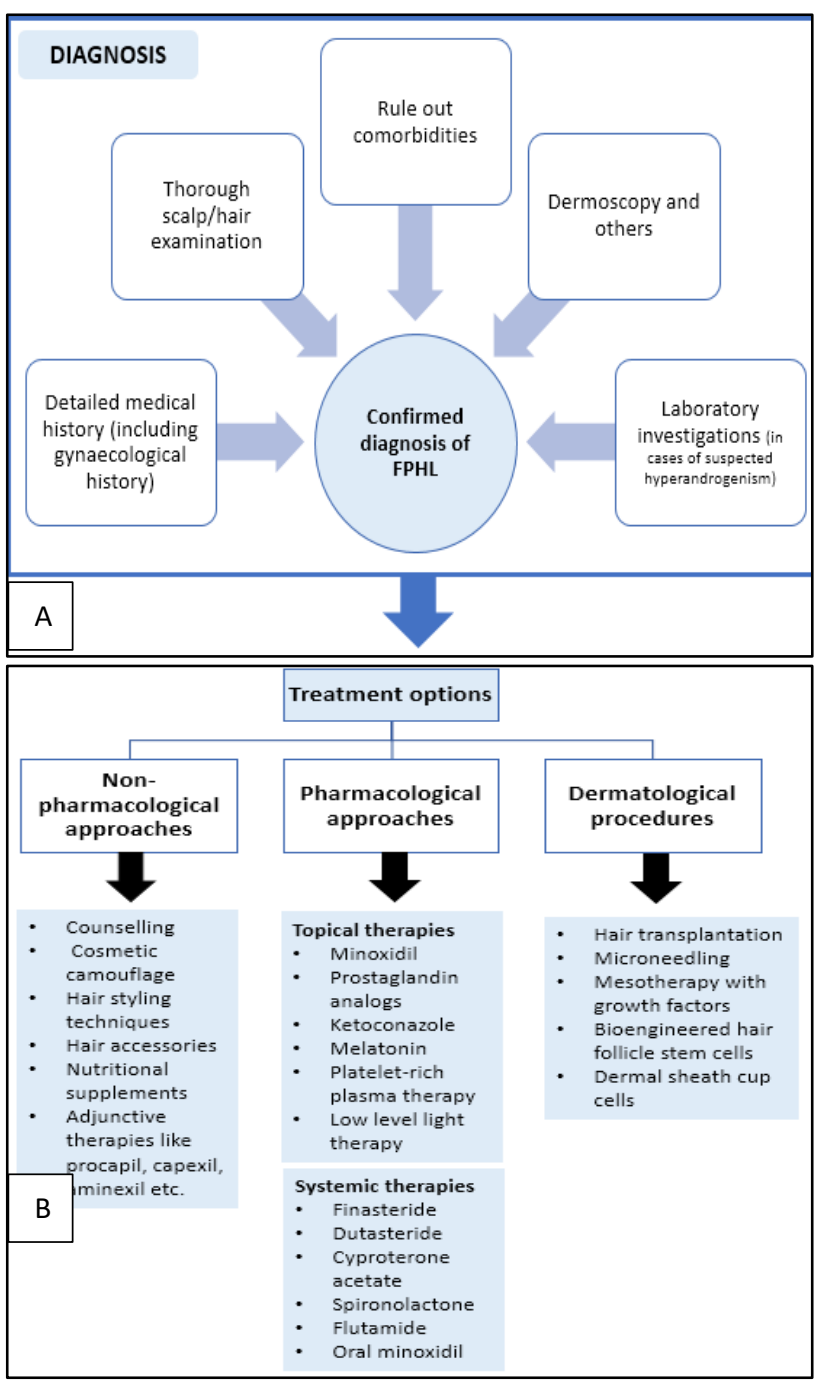

Figure 4 (A and B): Simplified diagnostic and treatment algorithm for FPHL.
TOPICAL MINOXIDIL: OPTIMAL USE IN CLINICAL PRACTICE

\section{Introduction}

Topical minoxidil has been the mainstay therapy for androgenetic alopecia till date. ${ }^{12}$ It is a hair growth stimulator which increases hair length and diameter. ${ }^{13}$ Topical minoxidil is available as solution and foam formulations. The solution contains alcohol and propylene glycol which are required for dissolving minoxidil and increase uptake in tissues. Formulations containing 2 and 5\% minoxidil are commonly used in scalp alopecia in patients above 18 years of age. ${ }^{13}$ Recently, the central drugs standard control organisation (CDSCO) has recommended the use of minoxidil $2 \%$ and $5 \%$ topical solution for treatment of FPHL in India. ${ }^{14}$

\section{Starting dose of topical minoxidil monotherapy}

Minoxidil 2\% solution twice daily has been proved effective in preventing progression and improving AGA in female patients. ${ }^{15}$ Numerous clinical trials in AGA patients treated with $2 \%$ or $5 \%$ minoxidil solution showed a remarkable increase in hair growth and decrease in hair loss. However, superior results were evident with the $5 \%$ formulation. ${ }^{12}$ The recommended treatment for male AGA is twice daily application of 1 $\mathrm{mL} \mathrm{5 \%} \mathrm{minoxidil} \mathrm{solution,} \mathrm{whereas} \mathrm{for} \mathrm{FPHL} \mathrm{it} \mathrm{is} \mathrm{twice}$ daily application of $1 \mathrm{~mL} 2 \%$ minoxidil solution and once daily $5 \%$ minoxidil foam. ${ }^{12}$ Minoxidil uptake is about $50 \%$ after an hour and $75 \%$ after 4 hours. ${ }^{13}$

\section{Preferred formulation and concentration of topical} minoxidil

Evidence has established the efficacy and safety of twicedaily application of minoxidil, with a concentration of $5 \%$ being superior to $2 \%$ minoxidil. ${ }^{16-18}$ However, more treatment-related local side effects, like facial hypertrichosis and contact dermatitis occur with $5 \%$ formulations. ${ }^{16}$ Furthermore, $5 \%$ minoxidil foam is more aesthetically pleasing to patients, associated with less facial hypertrichosis and interferes less with hair styling versus $2 \%$ solution. ${ }^{17,19,20}$ According to the multidisciplinary androgen excess and PCOS committee (2019), treatment of FPHL must begin with 5\% minoxidil, adding 5- $\alpha$-reductase inhibitors or antiandrogens when there is severe hair loss or associated hyperandrogenism. ${ }^{21}$ Table 2 provides a summary of clinical studies on topical minoxidil.

\section{Maintenance dose of topical minoxidil}

The 5\% minoxidil foam applied once daily is equivalent to $2 \%$ topical minoxidil solution applied twice daily in FPHL. ${ }^{12}$ Long-term use of minoxidil is essential for maintaining clinical results, as these effects regress with drug discontinuation. ${ }^{13}$ Minimum of 4-6 months of treatment needed for significant results with minoxidil. ${ }^{24}$ 
Table 2: Summary of clinical evidence for topical minoxidil.

\begin{tabular}{|c|c|c|c|}
\hline Study & $\begin{array}{l}\text { Concentration of } \\
\text { minoxidil }\end{array}$ & Results & Significance \\
\hline DeVillez et al (1994) & $\begin{array}{l}2 \% \text { topical } \\
\text { minoxidil solution } \\
\text { versus placebo }\end{array}$ & $\begin{array}{l}\text { Number of non-vellus hairs in a } 1-\mathrm{cm}^{2} \\
\text { evaluation site was increased by an average } \\
\text { of } 23 \text { hairs with } 2 \% \text { minoxidil and by an } \\
\text { average of } 11 \text { hairs with placebo }\end{array}$ & $\begin{array}{l}\text { Topical minoxidil was } \\
\text { significantly more } \\
\text { effective than placebo }\end{array}$ \\
\hline Lucky et al (2004) & $\begin{array}{l}\text { Twice-daily } 5 \% \\
\text { topical minoxidil, } \\
2 \% \text { topical } \\
\text { minoxidil and } \\
\text { placebo }\end{array}$ & $\begin{array}{l}\text { Mean difference hair density } / \mathrm{cm}^{2}(\mathrm{SD}) \\
\text { between baseline and end of study } \\
\text { 2\% MS: } 20.7(17.6) \\
\text { 5\% MS: } 26.0(19.5) \\
\text { Placebo: } 9.4(14.6)\end{array}$ & $\begin{array}{l}\text { At week } 48,5 \% \text { topical } \\
\text { minoxidil group } \\
\text { demonstrated statistical } \\
\text { superiority over } 2 \% \\
\text { topical minoxidil group } \\
\text { (patient assessment of } \\
\text { treatment benefit) }\end{array}$ \\
\hline $\begin{array}{l}\text { Piraccini et al } \\
(2011)^{23}\end{array}$ & $\begin{array}{l}\text { Twice-daily topical } \\
\text { application of } 5 \% \\
\text { minoxidil solution }\end{array}$ & $\begin{array}{l}\text { Total number of hairs/area of } 1 \mathrm{~cm} \\
\text { diameter increased by } 21,4 \% \text { (mean } \\
\text { number at baseline: } 210,6 \text {, mean number at } \\
\text { the end of the } 6 \text {-month study: } 255,8 \text { ) } \\
\text { Percentage of vellus hair/area of } 1 \mathrm{~cm} \\
\text { diameter reduced by } 1.83 \% \text { (mean } \\
\text { percentage of vellus hair at baseline: } \\
12,6 \% \text {; at the end of the study: } 10,3 \% \text { ) }\end{array}$ & $\begin{array}{l}\text { Effective in the treatment } \\
\text { of female AGA, with } \\
\text { evident efficacy already } \\
\text { after } 6 \text { months }\end{array}$ \\
\hline $\begin{array}{l}\text { Blume-Peytavi et al } \\
(2011)^{17}\end{array}$ & $\begin{array}{l}\text { Once-daily } 5 \% \\
\text { minoxidil topical } \\
\text { foam with twice- } \\
\text { daily } 2 \% \text { minoxidil } \\
\text { topical solution }\end{array}$ & $\begin{array}{l}\text { Mean difference hair density/cm }{ }^{2}(\mathrm{SD}) \\
\text { between baseline and end of study } \\
5 \% \text { MF: } 31.9(19.9) \\
2 \% \text { MS: } 28.4(19.9)\end{array}$ & $\begin{array}{l}\text { Once-daily } 5 \% \text { minoxidil } \\
\text { topical foam is noninferior } \\
\text { and as effective for } \\
\text { stimulating hair growth as } \\
\text { twice-daily } 2 \% \text { minoxidil } \\
\text { topical solution }\end{array}$ \\
\hline
\end{tabular}

\section{Minoxidil combined with adjuvant therapies}

Combining minoxidil with topical preparations like procapil, capexil, aminexil, and others may have additive effects. However, supporting evidence are lacking. Platelet-rich plasma (PRP) therapy can also be used as an adjuvant to minoxidil therapy. ${ }^{25}$ Khattab et al established that poly-l-lactic acid microthread therapy with minoxidil might improve hair density and hair thickness better compared to minoxidil alone. ${ }^{26}$

Esmat et al reported that low-level light therapy (LLLT) combined with 5\% minoxidil was superior to each monotherapy. The number of regrowing hair follicles significantly increased at 2 months with the combination. ${ }^{27}$ Likewise, Liu et al reported that the efficacy of LLLT could significantly improve when used with $5 \%$ minoxidil. ${ }^{28}$

\section{Consensus key-point 5}

According to experts, 5\% solution of minoxidil is preferred for FPHL in most of the cases (both starting and continuing treatment). In the Indian scenario, foam formulations have not been very popular and solutions are preferred over them. Maintainability of foam formulations in Indian weather has been an issue so far. In certain patients who cannot tolerate solutions, foams could be used for better compliance. For maintenance,
5\% minoxidil solution combined with other hair preparations like capexil could be employed in certain patients. Once-daily 5\% minoxidil is considered enough in case a patient finds twice-daily application inconvenient. As long as a person wants to maintain hair, minoxidil must be used. Minoxidil does not maintain hair regrowth when it is stopped.

\section{ASSESSMENT OF RESPONSE TO TOPICAL MINOXIDIL}

The clinical response to $5 \%$ topical minoxidil for treatment of AGA is typically observed after 4 to 6 months. ${ }^{1,24}$ Approximately $40 \%$ patients show a significative improvement. Hence, minoxidil response testing to rule out non-responders has notable clinical utility. When effective, minoxidil therapy must be continued indefinitely as discontinuation may induce telogen effluvium (TE) in minoxidil-dependent hair within 4 to 6 months. ${ }^{1}$ Paired comparison of photographs (pre/post treatment) using cameras with stereotactic positioning device could be used to track progress of hair loss and treatment response. ${ }^{11}$

\section{Consensus key-point 6}

The panel experts opined that paired comparison of photographs could be used to assess clinical response to minoxidil. One can start seeing the clinical response by 4 
months of treatment, while the peak could be seen by $6-9$ months.

\section{TREATMENT COMPLIANCE AND PATIENT COUNSELLING}

Although 5\% minoxidil solution has demonstrated promising results in FPHL, hypertrichosis is a common finding. Hypertrichosis could be problematic in women as it could result in poor treatment compliance. ${ }^{12}$ Minoxidil topical solutions free from propylene glycol could be a good alternative option for improving compliance and acceptability. ${ }^{29}$ Recently, the novel "After minoxidil" spray has proven to enhance ease of hair styling and reduced greasiness following application of topical minoxidil; thus, aiding improved drug compliance. It is a proprietary formulation containing aluminium starch octenylsuccinate, acrylates copolymer, and sodium bicarbonate. ${ }^{30}$ Most importantly, patients must be warned that during the first few months of minoxidil treatment, a transient increased shedding might occur. ${ }^{1}$ If unaware of the temporary shedding period, patients might discontinue using the minoxidil prematurely. ${ }^{31}$

Counselling is essential for addressing problems of lowered self-esteem and lowered quality of life. Psychotherapy and anxiolytic therapy could be considered in extreme cases. ${ }^{25}$ The physician must explain to the patient that 4-6 months of treatment are required to see significant results. Stopping treatment induces hair drop and a slow return to initial clinical state before treatment. ${ }^{24}$ Counselling about the possibility of hypertrichosis along with proper instructions on usage of minoxidil is important. ${ }^{25}$

\section{Consensus key-point 7}

The panel experts opined that minoxidil topical solutions free from propylene glycol could be a good alternative option for improving patient compliance.

\section{SIDE-EFFECTS, ALLERGY CONTRAINDICATIONS}

AND

The most common side effect of minoxidil solution is irritant contact dermatitis. Allergic contact dermatitis could occur due to propylene glycol or minoxidil itself. However, allergic reaction to minoxidil is infrequent. ${ }^{12}$ If patients are allergic to propylene glycol, replacing it with other vehicles like butylene glycol, glycerine or polysorbate could reduce sensitization. ${ }^{24}$ Moreover, the foam formulation which is free of propylene glycol must be prescribed instead. If reactions persist or allergy to minoxidil is suspected, all preparations must be discontinued. ${ }^{12}$

Minoxidil is contraindicated in patients with a history of hypersensitivity to the drug or its components like propylene glycol. Patients using topical minoxidil need regular monitoring for scalp changes and hypertrichosis. ${ }^{13}$ Twice daily application of topical minoxidil does not show systemic side effects like hypotension, abnormal heart rate, and weight gain. ${ }^{12}$ Minoxidil is not advised in pregnant and breastfeeding women, although it is neither teratogenic nor mutagenic. ${ }^{13,24}$ Overall, topical minoxidil solution has a favourable safety profile. ${ }^{24}$

\section{Consensus key-point 8}

The panel experts opined those newer formulations of 5\% minoxidil solution with less alcohol content have shown lesser side effects. Allergy to minoxidil itself is rare; allergy could usually occur with components like propylene glycol. If reactions persist after using foam or oral minoxidil, use of all minoxidil preparations must be discontinued.

\section{ORAL MINOXIDIL}

Low-dose oral minoxidil is generally well-tolerated in the majority of patients with FPHL and is a reasonable alternative in women who are intolerant or are unwilling to use topical minoxidil. ${ }^{1,32}$ In recent years, $2.5 \mathrm{mg}$ minoxidil has been acknowledged as a safe alternative for hair loss disorders in patients having difficulties with topical minoxidil preparations. ${ }^{31}$ However, oral minoxidil is associated with adverse effects like fluid retention, ischaemic heart disease, pulmonary hypertension, hypertrichosis, itchy eyes, skin rashes and polymenorrhea. $^{12}$

\section{Consensus key-point 9}

According to panel experts, oral minoxidil in lower doses could possibly be an alternative treatment to topical minoxidil. In cases of non-responders or allergy to topical minoxidil, oral minoxidil could be used. However, oral minoxidil increases the chance of hypertrichosis and swelling of the feet.

\section{MINOXIDIL IN COMBINATION WITH OTHER THERAPIES}

\section{Topical minoxidil in combination with anti-androgen therapies}

Mild-to-moderate FPHL can be treated with oral antiandrogen therapies and/or topical minoxidil with good results in many cases. ${ }^{1}$ Anti-androgen therapy is used in FPHL if hyperandrogenism is present or if there is a poor response to minoxidil. ${ }^{33}$ However, information on their efficacy is limited and they have not been approved by FDA. ${ }^{33,34}$ The commonly used antiandrogenic drugs in combination with minoxidil include 5-alpha reductase inhibitors (finasteride, dutasteride), spironolactone, flutamide, and cyproterone acetate. ${ }^{33}$ The summary of clinical trials of topical minoxidil combined with oral anti-androgens is given in Table $3 .^{35-37}$ 
Table 3: Summary of clinical evidence for topical minoxidil combined with oral anti-androgens.

\begin{tabular}{|c|c|c|}
\hline Study & Molecules & Significance \\
\hline $\begin{array}{l}\text { Hoedemaker et al } \\
(2007)^{35}\end{array}$ & $\begin{array}{l}200 \mathrm{mg} \text { spironolactone daily }+1 \mathrm{~mL} \text { twice } \\
\text { daily of minoxidil } 5 \% \text { solution }\end{array}$ & $\begin{array}{l}\text { Improvements had plateaued after spironolactone } \\
\text { monotherapy; further regrowth occurred with } \\
\text { addition of } 5 \% \text { minoxidil solution twice daily }\end{array}$ \\
\hline $\begin{array}{l}\text { Tanaka et al } \\
(2019)^{36}\end{array}$ & $\begin{array}{l}25 \mathrm{mg} \text { oral spironolactone once daily }+2.5 \\
\text { mg oral and } 5 \% \text { solution topical minoxidil } \\
\text { twice daily, and an injectable treatment }(2 \\
\mathrm{mL} \text { of } 0.5 \% \text { lidocaine, } 0.3 \mathrm{~mL} \text { of } 2 \% \\
\text { minoxidil, and } 1.7 \mathrm{~mL} \text { of hair regrowth } \\
\text { therapy injection) once monthly for }>6 \\
\text { months }\end{array}$ & $\begin{array}{l}95 \% \text { and } 96 \% \text { of patients reported satisfaction } \\
\text { with results after 6-and 12-months post-treatment, } \\
\text { respectively } \\
\text { The combination offers rapid and highly } \\
\text { efficacious treatment for FPHL with minimal } \\
\text { complications }\end{array}$ \\
\hline $\begin{array}{l}\text { Suchonwanit et al } \\
(2019)^{37}\end{array}$ & $\begin{array}{l}\text { Topical combination of } 0.25 \% \text { finasteride } \\
\text { and } 3 \% \text { minoxidil }\end{array}$ & $\begin{array}{l}\text { By } 24 \text { weeks, hair density and diameter had } \\
\text { increased in both groups, and } \\
\text { finasteride/minoxidil was significantly superior to } \\
\text { minoxidil solution in terms of hair diameter } \\
\text { ( } \mathrm{p}=0.039) \\
\text { This combination may be a promising treatment } \\
\text { option for FPHL with an additional benefit of } \\
\text { increasing hair diameter }\end{array}$ \\
\hline
\end{tabular}

Table 4: Summary of clinical evidence for topical minoxidil combined with dermatological procedures.

\begin{tabular}{|c|c|c|}
\hline Study & Molecules & Significance \\
\hline $\begin{array}{l}\text { Roenigk and } \\
\text { Berman }(1993)^{38}\end{array}$ & $\begin{array}{l}\text { Minoxidil } 2 \% \text { topical solution or placebo } \\
\text { applied to donor area for } 6 \text { weeks prior to } \\
\text { transplantation }\end{array}$ & $\begin{array}{l}\text { After } 17 \text { weeks, significantly less grafted hair was } \\
\text { lost by minoxidil-treated patients versus placebo- } \\
\text { treated patients ( } 22 \% \text { versus } 52 \% \text {; }=0.001) \text {. }\end{array}$ \\
\hline $\begin{array}{l}\text { Pakhomova et al } \\
(2020)^{39}\end{array}$ & PRP combined with $5 \%$ minoxidil & $\begin{array}{l}\text { Hair density increased by } 32 \% \\
\text { Mean hair shaft diameter increased by } 26 \% \\
\text { Intensity of hair loss decreased by } 39 \%\end{array}$ \\
\hline $\begin{array}{l}\text { Dhurat et al } \\
(2013)^{40}\end{array}$ & $\begin{array}{l}\text { Microneedling combined with } 5 \% \text { minoxidil } \\
\text { lotion }\end{array}$ & $\begin{array}{l}\text { Mean change in hair count at week } 12 \text { was } \\
\text { significantly greater for the micro needling } \\
\text { combined with minoxidil versus minoxidil } \\
\text { monotherapy ( } 91.4 \text { versus } 22.2 \text { respectively) }\end{array}$ \\
\hline
\end{tabular}

Topical minoxidil in combination with dermatological procedures

Topical minoxidil has been combined with various dermatological procedures. $^{38}$ Table 4 provides an overview of evidence on topical minoxidil combined with dermatological procedures. ${ }^{38-40}$

\section{Consensus key-point 10}

According to panel experts, anti-androgens are combined with minoxidil in clinical practice; however, there is paucity of data for the same. Finasteride has been commonly used in combination with minoxidil. In patients with hyperandrogenism, spironolactone could be used. However, the anti-androgen drug chosen could differ based on individual cases. Procedures like microneedling or PRP are adjuvant therapies to minoxidil. In early stages of hair loss, minoxidil can be used as monotherapy. In post-menopausal women having moderate-to-severe hair loss, minoxidil needs to be combined with other therapies based on individual case scenarios.

\section{CONCLUSION}

The article highlights effective management of FPHL based on experts' clinical views and evidence-based literature. Topical minoxidil continues to be the first-line treatment for hair loss in females as it provides substantial benefits. Topical minoxidil combined with other topical or systemic therapies including adjuvant therapies like procapil, capexil and aminexil or antiandrogen therapies like finasteride and spironolactone have shown favourable results. Also, topical minoxidil combined with dermatological procedures like micro needling, PRP or LLT has shown significant improvement in patients with AGA. However, there is a paucity of data regarding combination therapy, which necessitates further robust research.

\section{ACKNOWLEDGEMENTS}

Author would like to thanks to Scientimed solutions Pvt. Ltd. for assistance in developing the manuscript. 
Funding: Funding by unconditional educational grant from Dr Reddy's laboratories.

Conflict of interest: None declared

Ethical approval: Not required

\section{REFERENCES}

1. Fabbrocini G, Cantelli M, Masarà A, Annunziata MC, Marasca C, Cacciapuoti S. Female pattern hair loss: A clinical, pathophysiologic, and therapeutic review. Int J Womens Dermatol. 2018;4(4):203-11.

2. Ramos PM, Miot HA. Female Pattern Hair Loss: a clinical and pathophysiological review. An Bras Dermatol. 2015;90(4):529-43.

3. Bhat YJ, Saqib NU, Latif I, Hassan I. Female Pattern Hair Loss-An Update. Indian Dermatol Online J. 2020;11(4):493-501.

4. Rossi A, D'Arino A, Pigliacelli F, Caro G, Muscianese M, Fortuna MC et al. The diagnosis of androgenetic alopecia in children: Considerations of pathophysiological plausibility. Australas J Dermatol. 2019;60(4):e279-e83.

5. Herskovitz I, Tosti A. Female pattern hair loss. Int J Endocrinol Metab. 2013;11(4):e9860.

6. Gupta M, Mysore V. Classifications of Patterned Hair Loss: A Review. J Cutan Aesthet Surg. 2016;9(1):3-12.

7. Ludwig E. Classification of the types of androgenetic alopecia (common baldness) occurring in the female sex. Br J Dermatol. 1977;97(3):247-54.

8. Sinclair R, Wewerinke M, Jolley D. Treatment of female pattern hair loss with oral antiandrogens. $\mathrm{Br} \mathrm{J}$ Dermatol. 2005;152:466-73.

9. Vujovic A, Del Marmol V. The female pattern hair loss: review of etiopathogenesis and diagnosis. Biomed Res Int. 2014;2014:767628.

10. Dinh QQ, Sinclair R. Female pattern hair loss: current treatment concepts. Clin Interv Aging. 2007;2(2):189-99.

11. Singal A, Sonthalia S, Verma P. Female pattern hair loss. Indian J Dermatol Venereol Leprol. 2013;79:626-40.

12. Suchonwanit $\mathrm{P}$, Thammarucha $\mathrm{S}$, Leerunyakul K. Minoxidil and its use in hair disorders: a review. Drug Des Devel Ther. 2019;13:2777-86.

13. Minoxidil. Available at: https://www.ncbi.nlm.nih.gov/books/NBK482378/. Accessed on 4 August 2021.

14. Recommendations of the SEC (Dermatology \& Allergy) made in its 60th meeting held on 12.08.2021 at CDSCO HQ New Delhi. Available at https://cdsco.gov.in/opencms/resources/UploadCDS COWeb/2018/UploadCommitteeFiles/Recommendat ions \%20of\%20the\%20SECDermatologyAllergy.pdf. Accessed on 21 September 2021.

15. Kanti V, Messenger A, Dobos G, Reygagne P, Finner A, Blumeyer A, et al. Evidence-based (S3) guideline for the treatment of androgenetic alopecia in women and in men - short version. J Eur Acad Dermatol Venereol. 2018;32(1):11-22.
16. Ioannides D, Lazaridou E. Female pattern hair loss. Curr Probl Dermatol. 2015;47:45-54.

17. Blume-Peytavi U, Hillmann K, Dietz E, Canfield D, Garcia Bartels N. A randomized, single-blind trial of $5 \%$ minoxidil foam once daily versus $2 \%$ minoxidil solution twice daily in the treatment of androgenetic alopecia in women. J Am Acad Dermatol. 2011;65(6):1126-34.

18. Lucky AW, Piacquadio DJ, Ditre CM, Dunlap F, Kantor I, Pandya AG et al. A randomized, placebocontrolled trial of $5 \%$ and $2 \%$ topical minoxidil solutions in the treatment of female pattern hair loss. J Am Acad Dermatol. 2004;50(4):541-53.

19. Levy LL, Emer JJ. Female pattern alopecia: current perspectives. Int J Womens Health. 2013;5:541-56.

20. Purnak T, Senel E, Sahin C. Liquid formulation of minoxidil versus its foam formulation. Indian $\mathbf{J}$ Dermatol. 2011;56(4):462.

21. Carmina E, Azziz R, Bergfeld W, Escobar-Morreale $\mathrm{HF}$, Futterweit $\mathrm{W}$, Huddleston $\mathrm{H}$ et al. Female Pattern Hair Loss and Androgen Excess: A Report From the Multidisciplinary Androgen Excess and PCOS Committee. J Clin Endocrinol Metab. 2019;104(7):2875-91.

22. DeVillez RL, Jacobs JP, Szpunar CA, Warner ML. Androgenetic alopecia in the female. Treatment with 2\% topical minoxidil solution. Arch Dermatol. 1994;130(3):303-7.

23. Piraccini B, Starace M, Alessandrini A, Guarrera M, Fiorucci MC, Lorenzi S. Efficacy and tolerability of $5 \%$ minoxidil solution (Carexidil@) in male and female androgenetic alopecia: a 6-month open multicentric study. G Ital Dermatol Venereol. 2011;146(6-1):1-8.

24. Rossi A, Cantisani C, Melis L, Iorio A, Scali E, Calvieri S. Minoxidil use in dermatology, side effects and recent patents. Recent Pat Inflamm Allergy Drug Discov. 2012;6(2):130-6.

25. Mysore V, Parthasaradhi A, Kharkar RD, Ghoshal AK, Ganjoo A, Ravichandran $G$ et al. Expert consensus on the management of androgenetic alopecia in India. Int J Trichol. 2019;11:101-6.

26. Khattab FM, Bessar H. Accelerated hair growth by combining thread monofilament and minoxidil in female androgenetic alopecia. J Cosmet Dermatol. 2020;19(7):1738-44.

27. Esmat SM, Hegazy RA, Gawdat HI, Abdel Hay RM, Allam RS, El Naggar R et al. Low-level lightminoxidil 5\% combination versus either therapeutic modality alone in management of female patterned hair loss: A randomized controlled study. Lasers Surg Med. 2017;49(9):835-43.

28. Liu Y, Jiang LL, Liu F, Qu Q, Fan ZX, Guo Z et al. Comparison of low-level light therapy and combination therapy of 5\% minoxidil in the treatment of female pattern hair loss. Lasers Med Sci. 2021;36(5):1085-93.

29. Sarkar R, Vartak S, Acharya S, Kursam NK, Mane A, Mehta $S$ et al. Comparative Study to Evaluate Tolerability of Topical 5\% Minoxidil Novel 
Formulation and Alcohol-Based Conventional Solutions in Treatment of Androgenetic Alopecia in Indian Men: Randomized Double-Blind Study. Dermatol Ther (Heidelb). 2020;10(3):469-79.

30. Kovacevic M, McCoy J, Shapiro J, Sinclair R, VañoGalvan S, Goldust M et al. Novel "After Minoxidil" spray improves topical minoxidil compliance and hair style manageability. J Cosmet Dermatol. 2020;19(10):2647-9.

31. Randolph M, Tosti A. Oral minoxidil treatment for hair loss: A review of efficacy and safety. J Am Acad Dermatol. 2021;84(3):737-46.

32. Sinclair RD. Female pattern hair loss: a pilot study investigating combination therapy with low-dose oral minoxidil and spironolactone. Int $\mathrm{J}$ Dermatol. 2018;57(1):104-9.

33. Conic RR, Khetarpal S, Bergfeld W. Treatment of female pattern hair loss with combination therapy. Semin Cutan Med Surg. 2018;37(4):247-53.

34. Brough KR, Torgerson RR. Hormonal therapy in female pattern hair loss. Int J Womens Dermatol. 2017;3(1):53-7.

35. Hoedemaker C, van Egmond S, Sinclair R. Treatment of female pattern hair loss with a combination of spironolactone and minoxidil. Australas J Dermatol. 2007;48(1):43-5.

36. Tanaka Y, Aso T, Ono J. Combination Therapy to Treat Asian Female Pattern Hair Loss. J Cosmetics, Dermatol Sci Applications. 2019;9(3):216-22.
37. Suchonwanit P, Iamsumang W, Rojhirunsakool S. Efficacy of Topical Combination of $0.25 \%$ Finasteride and 3\% Minoxidil Versus 3\% Minoxidil Solution in Female Pattern Hair Loss: A Randomized, Double-Blind, Controlled Study. Am J Clin Dermatol. 2019;20(1):147-53.

38. Avram MR, Cole JP, Gandelman M, Haber R, Knudsen R, Leavitt MT et al. The potential role of minoxidil in the hair transplantation setting. Dermatol Surg. 2002;28(10):894-900.

39. Pakhomova EE, Smirnova IO. Comparative Evaluation of the Clinical Efficacy of PRP-Therapy, Minoxidil, and Their Combination with Immunohistochemical Study of the Dynamics of Cell Proliferation in the Treatment of Men with Androgenetic Alopecia. Int $\mathrm{J}$ Mol Sci. 2020;21(18):6516.

40. Dhurat R, Sukesh M, Avhad G, Dandale A, Pal A, Pund P. A randomized evaluator blinded study of effect of microneedling in androgenetic alopecia: a pilot study. Int J Trichol. 2013;5(1):6-11.

Cite this article as: Mysore V, Dhurat R, Abraham A, Thappa DM, Kumari P, Sarkar R et al. Optimal use of topical minoxidil in management of female pattern hair loss in India: an expert opinion. Int J Res Dermatol 2022;8:287-95. 